\title{
Restrição alimentar para suínos machos castrados e imunocastrados em terminação
}

\author{
Feeding restriction to finishing barrows and immunocastrated swine
}

\author{
Alexandre Pereira dos Santos ${ }^{\mathrm{I}}$ Charles Kiefer $^{\mathrm{II} *}$ Leandro Pereira Martins $^{\mathrm{I}}$ \\ Caiki Calepso Fantini ${ }^{1}$
}

\section{RESUMO}

O objetivo do trabalho foi avaliar o desempenho e as características quantitativas de carcaça de suínos machos castrados e imunocastrados, sob alimentação à vontade ou restrição quantitativa. Foram utilizados 240 animais, com peso

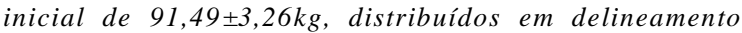
experimental de blocos ao acaso, em esquema fatorial $2 \times 2$ (dois manejos alimentares e duas categorias), com quatro repetições e 15 suínos cada. Suínos sob restrição alimentar apresentaram consumo inferior $(P<0,05)$ em relação aos alimentados à vontade. O consumo de ração não diferiu $(P>0,05)$ entre castrados e imunocastrados. Suínos alimentados à vontade apresentaram maior $(P<0,05)$ ganho de peso em relação àqueles sob restrição. Os imunocastrados apresentaram ganho de peso superior $(P<0,05)$ aos castrados. Houve interação $(P<0,05)$ entre manejo e categorias para conversão alimentar, em que a restrição melhorou a conversão alimentar dos castrados em relação aos imunocastrados. Além disso, os imunocastrados apresentaram melhor $(P<0,05)$ conversão alimentar em relação aos castrados, independente do manejo alimentar. Não houve interação $(P>0,05)$ entre os fatores sobre as características de carcaça. A restrição não afetou $(P>0,05)$ as características de carcaça. Machos imunocastrados apresentaram menor $(P<0,05)$ espessura de toucinho e maior percentual de carne magra na carcaça. A restrição alimentar melhora a conversão alimentar de machos castrados. A restrição alimentar piora o ganho de peso e não altera as características de carcaça dos machos castrados $e$ imunocastrados. Suínos imunocastrados apresentam desempenho superior, menor espessura de toucinho e maior percentual de carne magra em relação aos castrados.

Palavras-chave: carcaça, carne magra, desempenho, manejo alimentar.

\section{ABSTRACT}

The objective of this study was to evaluate the performance and carcass quantitative characteristics of barrows and immunocastrated swine fed ad libitum or under quantitative feeding restriction. Two hundred and forty animals were used, with initial weight of $91.49 \pm 3.26 \mathrm{~kg}$, distributed in a randomized blocks design, in a factorial scheme $2 \times 2$ (two management and two food categories), with four replicates of 15 pigs each. Pigs submitted to dietary restriction had lower consumption $(P<0.05)$ than those fed ad libitum. Feed intake did not differ $(P>0.05)$ between castrated and immunocastrated. Pigs fed ad libitum had higher $(P<0.05)$ weight gain over those submitted to restriction. The immunocastrated showed higher weight gain $(P<0.05)$ than castrated. There was an interaction $(P<0.05)$ between management and categories for feed, in which the restriction improved castrated pigs. Immunocastrated had better $(P<0.05)$ feed conversion compared to castrated, regardless of feed management. There was no interaction ( $P>0.05)$ among the factors on carcass traits. The restriction did not affect $(P>0.05)$ carcass traits. Immunocastrated pigs had lower $(P<0.05)$ back fat thickness and higher percentage of lean meat. Dietary restriction improves feed conversion of castrated pigs. The dietary restriction affects weight gain and does not affect carcass characteristics of barrows and immunocastrated. Immunocastrated pigs have higher performance, lower back fat thickness and a higher percentage of lean meat compared to the castrated.

Key words: carcass, lean meat, feeding management, performance.

'Universidade Federal de Mato Grosso do Sul (UFMS), Campo Grande, MS, Brasil.

IUFMS, 79074-460, Campo Grande, MS, Brasil. E-mail: charles.kiefer@ufms.br. *Autor para correspondência. 


\section{INTRODUÇÃO}

As potenciais vantagens da produção de suínos com alto peso de abate são reconhecidas pela indústria, dentre as quais estão o aumento da produção de carne por matriz alojada, aumento da produtividade na planta frigorífica e o aumento do peso dos cortes nobres da carcaça. Contudo, as maiores limitações na obtenção de animais com elevado peso de abate estão relacionadas aos teores de gordura na carcaça e sua associação com a redução na eficiência alimentar.

O percentual de carne magra na carcaça dos suínos pode ser incrementado pelo aumento na quantidade de proteína ou redução de gordura depositada ou ainda pela associação de ambos. Os suínos, especialmente na fase de terminação, tendem a alterar o consumo de ração, procurando ajustá-lo de acordo com o nível energético da dieta (REZENDE et al., 2006). Todavia, em situações de consumo à vontade e com elevada concentração energética na dieta, a quantidade de energia ingerida que é designada para deposição de gordura é maior que a destinada para deposição protéica, o que pode resultar no acúmulo acentuado de gordura na carcaça (PETTIGREW, 2001).

Uma estratégia de baixo custo que pode ser adotada visando à redução da deposição de gordura na carcaça de suínos abatidos com peso elevado é o manejo de restrição alimentar. A técnica de restrição alimentar pode ser aplicada de duas formas. A primeira consiste na redução da quantidade de ração fornecida, denominada de restrição alimentar quantitativa (BARBOSA et al., 2003). A segunda, baseia-se na redução da densidade de nutrientes da dieta, neste caso, denominada restrição alimentar qualitativa (MAZZUCO et al., 2000).

Além disso, as temperaturas ambientais, em grande parte do território brasileiro, apresentam-se acima do limite superior da zona de termoneutralidade (média superior a $25^{\circ} \mathrm{C}$ ) para suínos em fase de terminação, o que pode prejudicar o consumo voluntário de alimento. Nessas circunstâncias, a redução do consumo de alimento está relacionada à redução da produção endógena de calor, devido à dificuldade do suíno em dissipar calor corporal para o ambiente (WHITTEMORE et al., 2001).

Tem-se verificado ainda a carência de informações na literatura relacionadas à aplicabilidade da restrição alimentar, especialmente na criação de suínos machos castrados e imunocastrados. Nesse contexto, realizou-se este estudo com o objetivo de avaliar o desempenho e as características quantitativas de carcaça dessas categorias, na fase de terminação, alimentados à vontade ou sob regime de restrição alimentar quantitativa.

\section{MATERIAL E MÉTODOS}

O experimento foi conduzido na Suinocultura Rancho Alegre, no município de Campo Grande-MS. Foram utilizados 240 suínos, sendo 120 machos castrados cirurgicamente e 120 machos imunocastrados, de alto potencial genético, obtidos do cruzamento entre Duroc/Pietran x Large White/Landrace, com peso médio inicial de 91,49 $\pm 3,26 \mathrm{~kg}$.

Os animais foram alojados em baias de alvenaria, com piso de concreto e lâmina d'água, providas de comedouro semi-automático e bebedouro tipo chupeta. Foram distribuídos em delineamento experimental de blocos ao acaso, em esquema fatorial 2x2 (dois planos de alimentação: à vontade e restrito; e duas categorias animais: machos castrados cirurgicamente e machos imunocastrados), com quatro repetições e 15 suínos por unidade experimental. Na formação dos blocos, levou-se em consideração o peso inicial dos animais.

Os suínos machos foram submetidos ao procedimento cirúrgico ao sétimo dia de vida para a obtenção dos machos castrados. Para a obtenção dos animais imunocastrados, os suínos machos inteiros foram submetidos a duas doses de $2 \mathrm{~mL}$ de vacina, com aplicação subcutânea, sendo a primeira realizada 60 dias pré-abate e a segunda 31 dias pré-abate, de acordo com protocolo de imunização proposto por JAROS et al. (2005). O experimento teve início por ocasião da aplicação da segunda dose da vacina, quando os animais estavam com 137 dias de idade. Para a realização da imunocastração, foi utilizada vacina específica $\left(\right.$ Vivax $\left.^{\circledR}\right)$ à base de um análogo sintético incompleto do GnRF conjugado a uma proteína carreadora.

As dietas experimentais (Tabela 1) foram isonutritivas. Os animais submetidos ao plano de alimentação restrita receberam ração calculada para um nível de restrição de $10 \%$ em relação aos animais alimentados à vontade. $\mathrm{O}$ cálculo de restrição foi realizado diariamente, baseando-se no consumo médio do grupo alimentado à vontade no dia anterior.

As variações térmicas no interior no galpão foram monitoradas diariamente às 7, 12 e 17 horas, por termômetros de bulbo (seco e úmido) e de globo negro, instalados no centro do galpão. Os valores registrados foram convertidos no índice de temperatura de globo e umidade (ITGU), para caracterizar o ambiente térmico em que os animais foram mantidos.

Os animais foram pesados no início e ao término do experimento (168 dias de idade) para determinação do ganho de peso e da conversão alimentar. Ao final do experimento, os animais foram 
Tabela 1 - Composição percentual e nutricional calculada da dieta experimental.

\begin{tabular}{|c|c|}
\hline Ingredientes & $\%$ \\
\hline Sorgo baixo tanino & 70,05 \\
\hline Farelo de soja (45\%) & 18,20 \\
\hline Farinha de carne e ossos (41\%) & 8,30 \\
\hline Banha & 2,40 \\
\hline Sal comum & 0,60 \\
\hline Calcário & 0,30 \\
\hline Suplemento vitamínico/mineral ${ }^{1}$ & 0,15 \\
\hline \multicolumn{2}{|l|}{ Composição calculada² } \\
\hline Proteína bruta $(\%)$ & 15,39 \\
\hline Energia metabolizável $\left(\mathrm{kcal} \mathrm{kg}^{-1}\right)$ & 3240 \\
\hline Fósforo disponível (\%) & 0,66 \\
\hline Cálcio $(\%)$ & 1,02 \\
\hline Sódio $(\%)$ & 0,30 \\
\hline Lisina digestível (\%) & 0,69 \\
\hline Metionina + cistina digestível (\%) & 0,45 \\
\hline Triptofano digestível (\%) & 0,17 \\
\hline Treonina digestível (\%) & 0,53 \\
\hline Valina digestível (\%) & 0,72 \\
\hline
\end{tabular}

${ }^{1}$ Conteúdo por kg de produto: Vitamina A, 840.000UI; Vitamina $\mathrm{D}_{3}, 210.000 \mathrm{UI}$; Vitamina E, 1.522,5mg; Ácido fólico, 63mg; Pantotenato de cálcio, $1.680 \mathrm{mg}$; Biotina, 5,25mg; Niacina, $2.520 \mathrm{mg}$; Piridoxina, 210mg; Riboflavina, 588mg; Tiamina, $210 \mathrm{mg}$; Vitamina $B_{12}, 3.150 \mathrm{mg}$; Vitamina $K_{3}, 105 \mathrm{mg}$; Selênio, $63 \mathrm{mg}$; Colina, 65.250mg; Cobre, $30.000 \mathrm{mg}$; Zinco, $160.000 \mathrm{mg}$; Iodo, $1.900 \mathrm{mg}$; Ferro, $100.000 \mathrm{mg}$; Manganês, $70.000 \mathrm{mg}$; Cobalto, $375 \mathrm{mg}$; Selênio, $150 \mathrm{mg}$; veículo q.s.p.1000g.

${ }^{2}$ Calculada de acordo com níveis estabelecidos na tabela de Composição Nutricional de Alimentos (ROSTAGNO et al., 2005).

submetidos ao jejum de sólidos por 24 horas e transportados para o abatedouro. No abatedouro, os suínos foram alojados em baias coletivas de espera com acesso à vontade à água. Por ocasião do abate, todos os animais foram novamente pesados insensibilizados pelo método elétrico (eletronarcose), sacrificados pela secção dos grandes vasos do pescoço, escaldados e eviscerados.

Ao final da linha de abate, as carcaças foram pesadas e divididas longitudinalmente, e realizados cortes na metade esquerda, no ponto $\mathrm{P} 2$ ( $10^{\mathrm{a}}$ costela), para a determinação da profundidade do músculo e espessura de toucinho, de acordo com BRIDI \& SILVA (2007). A área de olho-de-lombo foi determinada utilizando-se uma folha de papel vegetal, a qual foi colocada em cima do lombo, contornando-o com o auxílio de uma caneta de retroprojetor. O desenho do músculo foi colocado sobre papel milimetrado, fazendose, assim, a contagem dos pontos localizados dentro da área demarcada, sendo que cada ponto representou uma área de $0,25 \mathrm{~cm}^{2}$. Foram medidos os comprimentos das carcaças a partir do bordo cranial da sínfise pubiana até o bordo cranial do atlas. $\mathrm{O}$ rendimento de carcaça quente foi calculado com base no peso de abatedouro e no peso de carcaça quente, conforme BRIDI \& SILVA (2007). O percentual de carne magra e o índice de bonificação foram determinados por meio de equações propostas por BRIDI \& SILVA (2007), sendo: carne magra $(\%)=60-($ espessura de toucinho $\times 0,58)+$ profundidade do músculo x 0,10 ; índice de bonificação $=23,6+0,286 \times$ Pcarq + Pcmf.

As variáveis de desempenho avaliadas foram os consumos de ração, proteína e de lisina, ganho de peso e conversão alimentar. As características de carcaça mensuradas foram peso e rendimento de carcaça quente, comprimento de carcaça, espessura de toucinho, profundidade de músculo, área de olhode-lombo, percentual de carne magra e o índice de bonificação.

Os dados obtidos foram submetidos à análise de variância pelo procedimento GLM. Os efeitos incluídos no modelo analítico foram os planos de alimentação, as categorias e a interação entre plano de alimentação e categoria. As eventuais diferenças entre as médias foram comparadas pelo teste $\mathrm{F}$. As análises estatísticas foram realizadas por intermédio do programa estatístico SAS, em nível de 5\% de significância.

\section{RESULTADOS E DISCUSSÃO}

Os valores médios de temperatura do ar, umidade relativa do ar, temperatura de globo negro e o ITGU registrados durante o experimento corresponderam a $28,8 \pm 2,6^{\circ} \mathrm{C}, 89,9 \pm 10,9 \%, 29,2 \pm 2,6^{\circ} \mathrm{C}$ e $80,1 \pm 3,2$, respectivamente. Pode-se inferir que a temperatura média do ar registrada durante o período experimental foi superior à temperatura crítica máxima de $27^{\circ} \mathrm{C}$ estabelecida para a categoria (SAMPAIO et al., 2004).

Não foi constatada interação $(\mathrm{P}>0,05)$ entre o manejo alimentar e as categorias para peso final, consumo de ração diário, ganho de peso diário e consumos de proteína digestível, lisina digestível e energia metabolizável (Tabela 2). Da mesma forma, não foi observado efeito $(\mathrm{P}>0,05)$ do manejo alimentar $\mathrm{e}$ das categorias avaliadas sobre o peso final dos animais.

Observou-se efeito $(\mathrm{P}<0,05)$ do manejo alimentar sobre o consumo de ração diário, em que os animais submetidos ao manejo de restrição alimentar apresentaram consumo $9,4 \%$ inferior em relação aos animais alimentados à vontade. Por outro lado, não foi constatada diferença $(\mathrm{P}>0,05)$ do consumo de ração diário entre machos castrados e imunocastrados. 
Tabela 2 - Peso inicial (PI), peso final (PF), consumo de ração (CR), ganho de peso (GP), conversão alimentar (CA), consumo de proteína digestível (CPD), consumo de lisina digestível (CLD) e consumo de energia metabolizável (CEM) de suínos machos castrados (MC) e imunocastrados (MI) sob alimentação à vontade (AV) e restrita (AR).

\begin{tabular}{|c|c|c|c|c|c|c|c|c|}
\hline \multirow[b]{2}{*}{ Variável } & \multirow[b]{2}{*}{$\mathrm{A}^{1}$} & \multicolumn{3}{|c|}{--------------C $\mathrm{C}^{2}$} & \multicolumn{3}{|c|}{-----------------Valor-P------------------ } & \multirow[b]{2}{*}{$\mathrm{CV}, \%$} \\
\hline & & $\mathrm{MC}$ & MI & Média & $A^{1}$ & $\mathrm{C}^{2}$ & $\mathrm{~A}^{1} \mathrm{x} \mathrm{C}^{2}$ & \\
\hline \multirow{3}{*}{ PI, kg } & $\mathrm{AV}$ & 93,07 & 90,66 & 91,86 & \multirow{3}{*}{0,659} & \multirow{3}{*}{0,165} & \multirow{3}{*}{0,977} & \multirow{3}{*}{3,64} \\
\hline & AR & 92,36 & 89,86 & 91,11 & & & & \\
\hline & Média & 92,72 & 90,26 & 91,49 & & & & \\
\hline \multirow{3}{*}{$\mathrm{PF}, \mathrm{kg}$} & $\mathrm{AV}$ & 123,76 & 125,43 & 124,59 & \multirow{3}{*}{0,090} & \multirow{3}{*}{0,862} & \multirow{3}{*}{0,395} & \multirow{3}{*}{2,55} \\
\hline & $\mathrm{AR}$ & 122,26 & 121,15 & 121,71 & & & & \\
\hline & Média & 123,01 & 123,29 & 123,15 & & & & \\
\hline \multirow{3}{*}{$\mathrm{CR}, \mathrm{g} \mathrm{dia}^{-1}$} & $\mathrm{AV}$ & 3.562 & 3.455 & $3.508_{\mathrm{a}}$ & \multirow{3}{*}{0,002} & \multirow{3}{*}{0,199} & \multirow{3}{*}{0,942} & \multirow{3}{*}{4,96} \\
\hline & $\mathrm{AR}$ & 3.240 & 3.121 & $3.180_{\mathrm{b}}$ & & & & \\
\hline & Média & 3.401 & 3.288 & 3.344 & & & & \\
\hline \multirow{3}{*}{$\mathrm{GP}, \mathrm{g} \mathrm{dia}^{-1}$} & AV & 990 & 1.122 & $1.056_{\mathrm{a}}$ & \multirow{3}{*}{0,049} & \multirow{3}{*}{0,016} & \multirow{3}{*}{0,193} & \multirow{3}{*}{6,16} \\
\hline & $\mathrm{AR}$ & 964 & 1.010 & $987_{b}$ & & & & \\
\hline & Média & $977_{\mathrm{B}}$ & $1.065_{\mathrm{A}}$ & 1.021 & & & & \\
\hline \multirow{3}{*}{$\mathrm{CA}$} & $\mathrm{AV}$ & $3,60_{\mathrm{Aa}}$ & $3,09_{\mathrm{Ba}}$ & 3,34 & \multirow{3}{*}{0,054} & \multirow{3}{*}{0,001} & \multirow{3}{*}{0,045} & \multirow{3}{*}{3,32} \\
\hline & AR & $3,36_{\mathrm{Ab}}$ & $3,09_{\mathrm{Ba}}$ & 3,23 & & & & \\
\hline & Média & 3,48 & 3,09 & 3,29 & & & & \\
\hline \multirow{3}{*}{ CPD, $\mathrm{g} \mathrm{dia}^{-1}$} & $\mathrm{AV}$ & 548 & 532 & $540_{\mathrm{a}}$ & \multirow{3}{*}{0,002} & & & \\
\hline & $\mathrm{AR}$ & 498 & 480 & $489_{b}$ & & 0,20 & 0,94 & 4,96 \\
\hline & Média & 523 & 506 & 515 & & & & \\
\hline & $\mathrm{AV}$ & 24 & 24 & $24_{a}$ & & & & \\
\hline CLD, $\operatorname{g~dia}^{-1}$ & AR & 22 & 22 & $22_{\mathrm{b}}$ & 0,006 & 0,28 & 1,00 & 5,82 \\
\hline & Média & 23 & 23 & 23 & & & & \\
\hline & $\mathrm{AV}$ & 11,54 & 11,19 & $11,37_{\mathrm{a}}$ & & & & \\
\hline CEM, Mcal dia ${ }^{-1}$ & $\mathrm{AR}$ & 10,50 & 11,11 & $10,30_{\mathrm{b}}$ & 0,002 & 0,20 & 0,94 & 4,96 \\
\hline & Média & 11,02 & 10,65 & 10,84 & & & & \\
\hline
\end{tabular}

Letras minúsculas diferentes na mesma coluna indicam diferença significativa $(\mathrm{P}<0,05)$.

Letras maiúsculas diferentes na mesma linha indicam diferença significativa $(\mathrm{P}<0,05)$.

${ }^{1} \mathrm{~A}=$ alimentação; ${ }^{2} \mathrm{C}=$ categoria.

Tem-se constatado que os suínos machos castrados apresentam consumo superior em relação aos inteiros (PAULY et al., 2008), cuja resposta tem sido relacionada à baixa concentração de testosterona nestes animais (DUNSHEA et al., 2001). Além disso, tem-se observado aumento da quantidade diária de alimento ingerido pelos machos inteiros quando comparados aos castrados, após a aplicação da segunda dose da vacina de imunocastração (ZAMARATSKAIA et al., 2008). Esse fato pode estar relacionado à queda abrupta dos níveis de testosterona nos suínos imunocastrados. No entanto, essa resposta não foi observada no presente estudo, identificandose com o resultado obtido por JAROS et al. (2005).

Comparando o consumo de ração diário de $3,508 \mathrm{~kg}$ para os animais mantidos sob regime de alimentação à vontade, com o consumo diário estimado de $3,571 \mathrm{~kg}$, apresentado por ROSTAGNO et al. (2005) para animais da mesma faixa de peso, genética e nutrição, pode-se inferir que as temperaturas ambientais registradas no transcorrer desta pesquisa, que foram superiores à temperatura crítica máxima, não influenciaram neste parâmetro. 
Constatou-se que os suínos submetidos à alimentação à vontade apresentaram ganho de peso diário aproximadamente $6,5 \%$ superior $(\mathrm{P}<0,05) \mathrm{em}$ relação aos submetidos à restrição alimentar. Também houve efeito $(\mathrm{P}<0,05)$ da categoria sobre o ganho, em que os imunocastrados apresentaram ganho de peso diário aproximadamente $8,3 \%$ superior aos castrados. Esse resultado corrobora o estudo de DUNSHEA et al. (2001), que também evidenciaram superioridade de $32 \%$ no ganho de peso dos suínos imunocastrados quando comparados aos castrados. A superioridade no desempenho dos imunocastrados em relação aos castrados na fase de terminação tardia pode ser considerada como um indicativo de exigências nutricionais diferenciadas para estas categorias.

Foi constatada interação significativa $(\mathrm{P}<0,05)$ entre o manejo alimentar e as categorias para a conversão alimentar, sendo que a restrição alimentar resultou em melhor $(\mathrm{P}<0,05)$ conversão alimentar para os suínos machos castrados em relação aos imunocastrados. Por sua vez, o manejo alimentar não influenciou $(\mathrm{P}>0,05)$ na conversão alimentar dos machos imunocastrados. Uma hipótese provável para esse resultado pode estar relacionada à composição de ganho da carcaça, com provável aumento da deposição de proteína diária em detrimento da redução da deposição de gordura na carcaça dos machos imunocastrados quando comparados aos castrados. Essa resposta também evidencia a possibilidade de redução da demanda energética para os machos castrados nesse período de produção.

Comparando o fator categoria, verificou-se que os suínos imunocastrados apresentaram melhor $(\mathrm{P}<0,05)$ conversão alimentar em relação aos castrados, independente do manejo alimentar ao qual foram submetidos. Portanto, os imunocastrados foram mais eficientes na utilização dos nutrientes da dieta, mesmo após a segunda dose da imunização, resposta que foi similar à observada por DUNSHEA et al. (2001) e ŠKRLEP et al. (2010a). Uma provável justificativa para esse resultado pode ser a existência temporária do efeito residual da produção endógena de hormônios anabólicos nos suínos imunocastrados.

Para o fator manejo alimentar, observou-se efeito $(\mathrm{P}<0,05)$ para os consumos de proteína e lisina digestível e energia metabolizável diários que foram de 9,4; 8,4 e 9,4\% superiores, respectivamente, para os suínos alimentados à vontade em relação aos submetidos ao manejo de restrição alimentar. Esses resultados estão coerentes com a redução de 9,4\% para o consumo de ração diário em função da restrição alimentar aplicada.
Não foi constatada interação ( $P>0,05)$ entre os fatores sobre as características quantitativas de carcaça avaliadas (Tabela 3). O manejo alimentar e as categorias não influenciaram $(\mathrm{P}>0,05)$ no peso e rendimento de carcaça quente, comprimento de carcaça, profundidade de músculo, área de olho-de-lombo e o índice de bonificação de carcaça.

Não foi constatado efeito $(\mathrm{P}>0,05)$ do fator manejo alimentar sobre a espessura de toucinho e o percentual de carne magra na carcaça. Contudo, houve efeito $(\mathrm{P}<0,05)$ do fator categoria sobre essas variáveis, em que os suínos imunocastrados apresentaram menor espessura de toucinho e maior percentual de carne magra na carcaça. $\mathrm{O}$ aumento do percentual de carne magra na carcaça, associado à redução da espessura de toucinho para suínos imunocastrados está coerente com a resposta observada para conversão alimentar.

Os dados obtidos nesta pesquisa corroboram os de LATORRE et al. (2008), que indicaram alta correlação entre deposição de proteína na carcaça, ganho de peso e conversão alimentar. A redução da espessura de toucinho e o aumento do percentual de carne magra na carcaça de suínos imunocastrados também foram constatados por JAROS et al. (2005), ZAMARATSKAIAet al. (2008) e ŠKRLEPet al. (2010b), sendo que esses pesquisadores obtiveram, respectivamente, superioridade de 1,4; 3,4 e 4,6\% para o percentual carne magra nos imunocastrados. No presente estudo, foi verificado teor de carne magra $3 \%$ maior $(\mathrm{P}<0,05)$ para os imunocastrados em relação aos castrados. Resultado que atesta a superioridade das características quantitativas de carcaça dos suínos imunocastrados.

\section{CONCLUSÃO}

A restrição alimentar quantitativa melhora a conversão alimentar de suínos machos castrados. A restrição alimentar piora o ganho de peso e não altera as características de carcaça dos suínos machos castrados e imunocastrados. Suínos imunocastrados apresentam desempenho superior, menor espessura de toucinho e maior percentual de carne magra em relação aos castrados.

\section{COMITÊ DE ÉTICA E BIOSSEGURANÇA}

Comissão de ética no uso de animais/UFMS, sob protocolo no 314/2011. 
Tabela 3 - Peso de carcaça quente (PCQ), rendimento de carcaça quente (RCQ), comprimento de carcaça (CC), espessura de toucinho (ET), profundidade de músculo (PM), área de olho-de-lombo (AOL), percentual de carne magra (PCM) e índice de bonificação (IB) de suínos machos castrados (MC) e imunocastrados (MI) sob alimentação à vontade (AV) e restrita (AR).

\begin{tabular}{|c|c|c|c|c|c|c|c|c|}
\hline \multirow{2}{*}{ Variável } & \multirow{2}{*}{$\mathrm{A}^{1}$} & \multicolumn{3}{|c|}{ - } & \multicolumn{3}{|c|}{ - Valor-P--_- } & \multirow{2}{*}{$\mathrm{CV}, \%$} \\
\hline & & $\mathrm{MC}$ & MI & Média & $\mathrm{A}^{1}$ & $\mathrm{C}^{2}$ & $\mathrm{~A}^{1} \mathrm{x} \mathrm{C}^{2}$ & \\
\hline \multirow{3}{*}{ PCQ, kg } & $\mathrm{AV}$ & 101,442 & 94,333 & 97,49 & \multirow{3}{*}{0,701} & \multirow{3}{*}{0,072} & \multirow{3}{*}{0,409} & \multirow{3}{*}{9,89} \\
\hline & $\mathrm{AR}$ & 100,100 & 97,542 & 98,82 & & & & \\
\hline & Média & 100,771 & 95,759 & 98,12 & & & & \\
\hline \multirow{3}{*}{$\mathrm{RCQ}, \%$} & AV & 85,480 & 85,188 & 85,30 & \multirow{3}{*}{0,888} & \multirow{3}{*}{0,642} & \multirow{3}{*}{0,812} & \multirow{3}{*}{3,91} \\
\hline & $\mathrm{AR}$ & 85,700 & 84,767 & 85,10 & & & & \\
\hline & Média & 85,590 & 84,965 & 85,20 & & & & \\
\hline \multirow{3}{*}{$\mathrm{RC}, \mathrm{cm}$} & $\mathrm{AV}$ & 100,750 & 101,467 & 101,15 & \multirow{3}{*}{0,809} & \multirow{3}{*}{0,496} & \multirow{3}{*}{0,946} & \multirow{3}{*}{3,43} \\
\hline & $\mathrm{AR}$ & 100,583 & 101,167 & 100,88 & & & & \\
\hline & Média & 100,667 & 101,333 & 101,02 & & & & \\
\hline \multirow{3}{*}{$\mathrm{ET}, \mathrm{mm}$} & AV & 14,500 & 11,067 & 12,59 & \multirow{3}{*}{0,226} & \multirow{3}{*}{0,016} & \multirow{3}{*}{0,601} & \multirow{3}{*}{33,26} \\
\hline & $\mathrm{AR}$ & 12,500 & 10,250 & 11,38 & & & & \\
\hline & Média & $13,500_{\mathrm{A}}$ & $10,704_{B}$ & 12,02 & & & & \\
\hline \multirow{3}{*}{$\mathrm{PM}, \mathrm{mm}$} & AV & 61,917 & 63,933 & 63,04 & \multirow{3}{*}{0,698} & \multirow{3}{*}{0,386} & \multirow{3}{*}{0,864} & \multirow{3}{*}{11,29} \\
\hline & $\mathrm{AR}$ & 61,500 & 62,833 & 62,17 & & & & \\
\hline & Média & 61,708 & 63,444 & 62,63 & & & & \\
\hline \multirow{3}{*}{$\mathrm{AOL}, \mathrm{cm}^{2}$} & AV & 51,000 & 47,127 & 48,85 & \multirow{3}{*}{0,206} & & & \\
\hline & $\mathrm{AR}$ & 52,875 & 51,108 & 51,99 & & 0,197 & 0,654 & 16,47 \\
\hline & Média & 51,938 & 48,896 & 50,33 & & & & \\
\hline & AV & 57,782 & 59,975 & 59,00 & & & & \\
\hline PCM, \% & $\mathrm{AR}$ & 58,900 & 60,338 & 59,62 & 0,270 & 0,008 & 0,562 & 3,88 \\
\hline & Média & $58,341_{\mathrm{B}}$ & $60,136_{\mathrm{A}}$ & 59,29 & & & & \\
\hline & $\mathrm{AV}$ & 110,395 & 110,554 & 110,48 & & & & \\
\hline IB & $\mathrm{AR}$ & 111,128 & 111,835 & 111,48 & 0,180 & 0,631 & 0,717 & 2,41 \\
\hline & Média & 110,761 & 111,124 & 110,95 & & & & \\
\hline
\end{tabular}

Letras minúsculas diferentes na mesma coluna indicam diferença significativa $(\mathrm{P}<0,05)$.

Letras maiúsculas diferentes na mesma linha indicam diferença significativa $(\mathrm{P}<0,05)$.

${ }^{1} \mathrm{~A}=$ alimentação; ${ }^{2} \mathrm{C}=$ categoria.

\section{REFERÊNCIAS}

BARBOSA, H.C.A. et al. Qualidade da carcaça de suínos em terminação alimentados com diferentes níveis de restrição alimentar e de energia na dieta. Arquivo Brasileiro de Medicina Veterinária e Zootecnia, v.55, p.606-614, 2003. Disponível em: <http:// www.scielo.br/scielo.php? script $=$ sci_arttext\&pid=S010209352003000500015>. Acesso em: 10 out. 2010. doi: 10.1590/ S0102-09352003000500014.

BRIDI, A.M.; SILVA, C.A. Métodos de avaliação de carcaça e da carne suína. Londrina: Midiograf, 2007. 97p.

DUNSHEA, F.R. et al. Vaccination of boars with a GnRH vaccine (Improvac) eliminates boar taint and increases growth performance. Journal of Animal Science, v.79, p.25242535, 2001. Disponível em: <http://www.animal-science.org/ content/79/10/2524.full.pdf+html>. Acesso em: 05 out. 2010.

JAROS, P. et al. Effect of active immunization against GnRH on androstenone concentration, growth performance and carcass quality in intact male pigs. Livestock Production Science, v.92, p.3138, 2005. Disponível em: <http://www.sciencedirect.com/science/ article/pii/S0301622604001241>. Acesso em: 12 out. 2010. doi: 10.1016/j.livprodsci.2004.07.011.

LATORRE, M.A. et al. The relationship within and between production performance and meat quality characteristics in pigs from three different genetic lines. Livestock Science, v.115, p.258-267, 2008. Disponível em: <http://www.sciencedirect.com/ 
science/article/pii/S1871141307004398>. Acesso em: 22 set. 2010. doi:10.1016/j.livsci.2007.08.013.

MAZZUCO, H. et al. Efeito da restrição alimentar qualitativa sobre o ganho compensatório em frangos de corte. Pesquisa Agropecuária Brasileira, v.35, p.543-549, 2000. Disponível em: <http://www.scielo.br/pdf/\%0D/pab/v35n3/v35n3a09.pdf>. Acesso em: 07 out. 2010.

PAULY, C. et al. Performances, meat quality, and boar taint of castrates and entire male pigs fed a standard and a raw potato starch-enriched diet. Animal, v.2, p.1707-1715, 2008. Disponível em: <http://www.db-alp.admin.ch/de/publikationen/ docs/pub_PaulyC_2008_19094.pdf>. Acesso em: 10 out. 2010. doi: $10.1017 / \mathrm{S} 1751731108002826$.

PETTIGREW, J.E.; ESNAOLA, M.A. Swine nutrition and pork quality: a review. Journal of Animal Science, v.79, p.E316-E342, 2001. Disponível em: <http://jas.fass.org/ content/79/E-Suppl/E316.full.pdf>. Acesso em: 15 set. 2010.

REZENDE, W.O. et al. Níveis de energia metabolizável mantendo a relação lisina digestível:caloria em rações para suínos machos castrados em terminação. Revista Brasileira de Zootecnia, v.35, p.1101-1106, 2006. Disponível em: <http:/ /www.scielo.br/pdf/rbz/v35n3s0/30723.pdf>. Acesso em: 05 set. 2010. doi: 10.1590/S1516-35982006000400022.

ROSTAGNO, H.S. et al. Tabelas brasileiras para aves e suínos: composição de alimentos e exigências nutricionais. 2.ed. Viçosa: UFV, 2005. 186p.

SAMPAIO, C.A.P. et al. Avaliação do ambiente térmico em instalações para crescimento e terminação de suínos utilizando os índices de conforto térmico nas condições tropicais. Ciência Rural, v.34, p.785-790, 2004. Disponível em: <http:// w w w.s c i e lo.br/s ci e 1 o.ph p ? p id = S 0103 -
$84782004000300020 \&$ script=sci_arttext $>$. Acesso em: 05 set. 2010. doi: 10.1590/S0103-84782004000300019.

ŠKRLEP, M. et al. Effect of immunocastration (improvac ${ }^{\circledR}$ ) in fattening pigs I: growth performance, reproductive organs and malodorous compounds. Slovenian Veterinary Research, v.47, p.57-64, 2010a. Disponível em: <http://www.slovetres.si/ files/pdf/volume2010/vol47_2/SlovVetRes_47_2_57-64.pdf〉. Acesso em: $10 \mathrm{dez} .2010$.

ŠKRLEP, M. et al. Effect of immunocastration (improvac ${ }^{\oplus}$ ) in fattening pigs II: carcass traits and meat quality. Slovenian Veterinary Research, v.47, p.65-72, 2010b. Disponível em: <http://www.slovetres.si/files/pdf/volume2010/vol47_2/ SlovVetRes_47_2.pdf\#page=32>. Acesso em: 10 dez. 2010.

TURKSTRA, J.A. et al. Performance of male pigs immunized against GnRH is related to the time of onset of biological response. Journal of Animal Science, v.80, p.2953-2959, 2002. Disponível em: <http://www.animal-science.org/content/ 80/11/2953.full.pdf+html>. Acesso em: 15 set. 2010.

WHITTEMORE, C.T. et al. Technical review of the energy and protein requirements of growing pigs: food intake. Animal Science, v.73, p.3-17, 2001. Disponível em: <http:// w w w. p i n k m on g o o s e. co.uk / P D F D u m p / WhittemoreGreenKnap2001(protein).pdf >. Acesso em: 05 set. 2010.

ZAMARATSKAIA, G. et al. Effect of a gonadotropin-releasing hormone vaccine (improvac ${ }^{\mathrm{TM}}$ ) on steroid hormones, boar taint compounds and performance in entire male pigs. Reproduction in Domestic Animals, v.43, p.351-359, 2008. Disponível em: <http://onlinelibrary.wiley.com/doi/10.1111/ j.1439-0531.2007.00914.x/pdf>. Acesso em: 05 set. 2010. doi: $10.1111 / \mathrm{j} .1439-0531.2007 .00914 . x$. 